\title{
Resilience modeling concepts in transportation systems: a comprehensive review based on mode, and modeling techniques
}

\author{
Shofiq Ahmed and Kakan Dey (1)
}

\begin{abstract}
The objective of this comprehensive review study was to compile a state-of-the-art understanding of the resilience of the transportation system due to natural and man-made disasters. This study identified resilience measurement parameters that can be used to formulate resilience quantification and improvement strategies of a transportation system. Reviewed articles were classified and summarized from two perspectives: (i) modeling based on the mode of transportation; and (ii) modeling based on the mathematical technique used to quantify resilience. One of the unique contributions of this review article is that it compiled the key resilience indices that were analyzed to quantify resilience. This review revealed that the majority of the scholarly articles on the topic of transportation system resilience published since 2006, were focused on the resilience of the roadway-based transportation system, and vulnerability was one of the most explored resilience indices in evaluating transportation system resilience. Several future research directions were identified considering the implications of emerging transportation technologies (e.g., connected and automated vehicle technology). The complex interdependency among critical infrastructure systems such as power, transportation, and communication system, as well as the cybersecurity issues in the advanced intelligent transportation system, will be vital in the resilience analysis of future transportation systems.
\end{abstract}

Keywords: Resilience modeling, Resilience index, Vulnerability index, Accessibility index, Reliability

\section{Introduction}

Disruptive events, whether it is predictable or unpredictable, natural or man-made, have widespread impacts on transportation system performance and availability. The higher frequency and severity of natural disasters in recent years show a worsening trend and challenges the resilience of critical infrastructure systems. In 2017, 16 natural disaster events caused more than billion-dollar damage per event in the United States alone [125]. These events included one drought event (North Dakota, South Dakota, and Montana), two flooding events

\footnotetext{
*Correspondence: kakan.dey@mail.wvu.edu

Department of Civil and Environmental Engineering, West Virginia University, Morgantown, WV, USA
}

\section{Springer Open}

(affected California, Missouri, and Arkansas), one extreme snowfall event (affected Southeast states including South Carolina, Florida, Virginia.), eight severe storm events (affected several Southeast and Midwestern states), three tropical cyclone events (affected Texas, Florida, and Puerto Rico), and one wildfire event (in California). The total death toll of these disasters was 362. While the occurrence of disruptive events (specifically natural disasters) is unavoidable, developing a proper mitigation and response plan to minimize the impact of such events is critical [122]. The adaptation and mitigating of emissions can reduce the impacts of climate change, which eventually decreases the occurrence of natural disasters [122]. A resilient system is 
capable of minimizing the disaster impacts with its inherent ability to maintain the reasonable performance of system components and enables the rapid restoration of the system. Therefore, to measure and improve the resilience of a system, the quantitative and qualitative modeling to understand the resilience properties and indicators of the transportation system is critical. The resilience of transportation systems can be defined with ten dimensions-(i) redundancy (i.e., same functionality of multiple components), (ii) diversity (i.e., different functionality), (iii) efficiency (i.e., demand and supply optimization), (iv) components' dependency (i.e., ability to operate independently), (v) strength (i.e., ability to withstand an event), (vi) stakeholders' collaboration (i.e., information and resource sharing among multiple entities of the system), (vii) adaptability (i.e., flexibility in the system elements), (viii) mobility performance (reaching destinations within a reasonable time), (ix) safety performance (i.e., less fatal/injury crashes), and $(x)$ the ability to recover quickly (i.e., rapid restoration with minimal intervention) [100]. While studies on understanding and defining social resilience due to disruptive events started early in the 1970s [120], studies focusing on transportation system resilience began in the 1990s [36]. Since then, many research studies on quantitative and qualitative modeling of transportation system resilience were conducted to facilitate resilience planning and emergency management.

Though the review articles on the transportation system resilience research are limited, there are a few outstanding review articles. For example, [45] classified articles on transportation system resilience based on qualitative and quantitative approaches considering performance metrics, analysis method, life-cycle phase, and modeling techniques. Two review articles on system resilience defined different domain-specific resilience for environmental multi-hazards and discussed the challenges and opportunities in resilience quantification [11, $69,129]$. reviewed the modeling of real-time vehicle schedule recovery methods of different modes (e.g., vehicle rescheduling, train rescheduling). This article reviewed the techniques of rescheduling trips due to the impact of a single or simultaneous impact of multiple severe disruptions that may include vehicle breakdowns and accidents considering different modes of transportation [133]. carried out a comprehensive review of the studies on resilience performance of the transportation system and reviewed articles that pre-dominantly analyzed the resilience performance parameters. A recent study by $\mathrm{Gu}$ et al. [61] reviewed articles on transportation performance under perturbations prioritizing reliability, vulnerability, and resilience parameters. While earlier studies on the transportation system resilience mostly focused on the conceptual framework-based model, more recent studies explored the different disruption scenarios to analyze the transportation system performance. Though there are few review articles on the transportation system resilience, this article adopted a unique approach of categorizing articles to provide a comprehensive undersending of the resilience of the transportation system. In general, research articles in transportation system resilience develop mathematical or conceptual models to quantify resilience in which authors develop a model based on the key contributing factors, apply models considering different infrastructural components and different disruption scenarios, and compare them with the existing models or discuss the limitations. In this review, the authors have developed the overarching concept of the two-perspective review methodology based on two questions:- (a) How different transportation modes perform in terms of transportation system resilience?; and (b) Which modeling and analysis techniques can be utilized to quantify resilience and develop the performance improvement strategy? In addition, one of the unique contributions of this paper is the identification and classification of the diverse resilience indices used in the literature to quantify transportation system resilience (discussed in section 4). This compilation will be much useful to the researchers in understanding the state of the art of resilience metrics at a glance.

The paper is organized as follows. Section 2 illustrates a summary of historical trends of disaster and impacts; Section 3 explains the methodology of the literature review; Section 4 presents the classification of different resilience indices; Sections 5 and 6 reviewed resilience studies in two categories - based on the mode of transportation, and based on the modeling techniques; Section 7 summarizes the reviewed articles; Section 8 identifies future research directions. Finally, Section 9 summarizes concluding remarks.

\section{Historical background of disaster and associated impact}

Disasters cause great disruptions not only to the transportation system but also to many other critical civil infrastructures, including power distribution, social and economic sectors. The impacts depends on the type and intensity of extreme weather events. Depending on the severity of the events and system resilience characteristics, impacts could vary from partial to a full closure of the system, traffic diversions to complete failure of the infrastructure. Drastic climate change includes seasonal heat waves, increment in arctic temperatures, sea-level rise, seawater temperature rise, which are major factors contributing to frequent and severe natural disasters [104]. 
Major hurricanes in the United States (US) caused significant damage since 1900. For example, hurricane Galveston (1900) affected several countries- Cuba, the southeastern Gulf of Mexico, the Texas coast in the US, and claimed 8000 lives and enormous property damage worth of $\$ 30$ million [124]. The Miami hurricane produced the highest sustained winds ever recorded before and caused property damage worth $\$ 90$ billion in 1926 [124]. According to a Red Cross report, the death toll was 373 human lives and 6381 injuries. The New England hurricane (1938) passed through the north part of Puerto Rico as a category five hurricane and hit Long Island and Connecticut as a category three hurricane. It caused 600 fatalities and infrastructure damage worth $\$ 308$ million [124]. The combination of strong winds, storm surges, and rainfalls during Hurricane Camille in 1969 caused 256 deaths, \$1.421 billion worth damage, and affected areas included most of the Gulf Coast, and Cuba [124]. Hurricane Gilbert (1988) was one of the few hurricanes that affected a very large geographic region, including several countries- Honduras, Dominican Republic, Mexico, Jamaica, United States, Haiti, Guatemala, Venezuela, Costa Rica, and Nicaragua claiming 318 lives [124]. Hurricane Andrew in 1992 was the third most intense hurricane in terms of the central pressure at landfall (27.23 in.) [124]. Hurricane Katrina in 2005 is one of the costliest hurricanes in the US, which caused damages worth $\$ 75$ billion [124]. Hurricane Sandy was the deadliest disaster in 2012 and was the secondcostliest hurricane causing damages worth $\$ 70.9$ billion [126]. Because of the flooding and power outages in New York and New Jersey due to Hurricane Sandy, the operations of most of the transportation infrastructure systems, including airports, seaports, and public transit systems, were shut down for several days [114]. Hurricane Maria made landfall in southeast Puerto Rico and caused damages worth $\$ 90.9$ billion [124]. It was a category four hurricane that was responsible for widespread devastation to not only transportation but also agriculture, communication, and energy infrastructure.

Geophysical disasters such as earthquakes also have a significant effect on transportation systems, and the most concerning factor is that they are difficult to predict. One of the most extreme earthquakes, the Tohoku earthquake of 2011, caused extensive damage to the transportation infrastructure of Japan. Japanese automobile production dropped by approximately $50 \%$ due to this disaster [127]. The Sichuan earthquake in China was the deadliest and caused 87,587 deaths and a total economic loss of $\$ 86$ billion ([123]). The landslides and rock-falls damaged more than $53,000 \mathrm{~km}$ of roads [127].

Along with roadway transportation, disruptive events have impacts on other modes of transportation too. For example, due to the terrorist attack on the World Trade Center in New York City on September 11, 2001, North American airspace was ordered to shut down their operations completely and for the first time in history, along with American airspace, Canadian airspace was also shut down to tackle the security threat [114]. Almost 235 flights had to do an emergency landing in Canada, and the airway operations between the Canadian and American airspace were greatly affected for three consecutive days [114]. Due to the refund of canceled flights and the additional costs of rerouting remaining passengers, the airline industry faced huge economic loss due to this event.

Many other types of natural disaster events impact the transportation system performance. For instance, a volcanic eruption in Iceland in 2010 produced large quantities of ash and affected the whole of Western Europe. As aircraft weather radar is not capable of detecting the presence of volcanic ash, aviation authorities startled and decided to shut down the operations of airports [114]. As a result, it became the largest natural disruption in the history of air transportation closing down the operation of major European airlines such as British Airways, Lufthansa. This disastrous event impacted $29 \%$ of the global air market, which was equivalent to 1.2 million passengers per day. Almost 100,000 flights were canceled and resulted in a total economic loss of $\$ 1.7$ billion [114].

In 2017, the natural disaster events and associated impacts set new records in terms of damage cost and economic loss. There were 16 weather and climate disaster events with cumulative damage of $\$ 306.2$ billion in the US [125]. These events included droughts, flooding, freeze events, severe storms, hurricanes, and wildfires. Among them, Hurricane Harvey became the costliest hurricane in the history of the US, costing about $\$ 125$ billion [125].

\section{Literature review methodology}

Many published articles on different aspects of transportation system performance and resilience defined resilience, quantified resilience parameters, evaluated resilience improvement strategy, and modeled transportation system performance. The primary scope of this review paper is confined to the resilience and the overall system performance due to the natural or man-made disaster impact. Though many studies from the late 1990s were reviewed, primarily emphasize was on the most recent studies from the last decade. The selected articles were classified from the perspective of different transportation system mediums, different modeling techniques, and different disaster types.

Figure 1 provides a summarized overview of the main sections and sub-sections of this research paper. All 


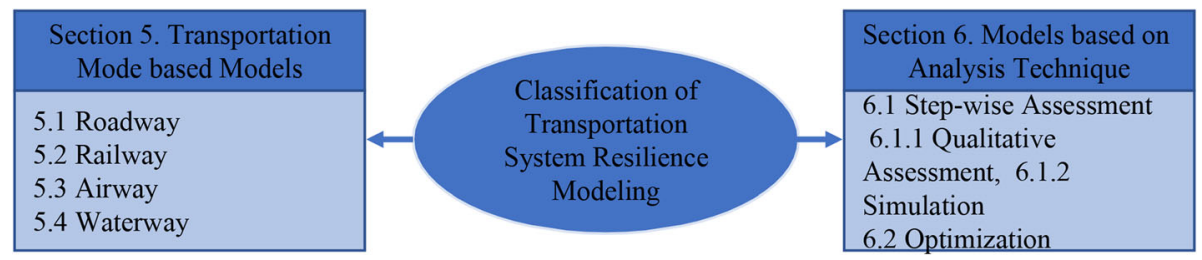

Fig. 1 Categorization of different sections and subsections of this review article on the transportation system resilience

articles were classified into major two domains: (i) Models based on the mode of transportation, (presented in Section 5), and (ii) Models based on the analysis technique (presented in Section 6).

\section{Resilience index}

Resilience, in general, defined as a system's ability to resist and absorb the impact of disruptions [25]. According to [105], resilience is a system's property that is identifiable whenever the system responds to demand through time. Dekker et al. [40] proposed resilience as following; 'A resilient system can adjust its' functioning prior to, during, and following changes and disturbances, so that it can continue to perform as required after a disruption or a major mishap, and in the presences of continuous stresses.' Researchers used several parameters, performance characteristics, or evaluation criteria to quantify the resilience and measure the potential impacts of a disruption scenario to a transportation system. While most studies on transportation systems resilience adopted specific parameter/resilience index, this terminology has seldom used in transportation system performance-based studies. This section summarized performance metrics that can be identified as resilience indexes.

\section{Travel time}

Travel time is the time spent in traveling from trip origin to destination and substantially dependent on the topographical features of the transportation system and meteorological conditions during a disaster scenario. As disasters can affect the topographical features (i.e., road network links) as well as travel time significantly, travel time is one of the most used parameters to quantify system performance in a disaster scenario. Travel time has been used to identify the difference in the performance of a transportation system in pre- and post-disaster time $[46,118]$. Researchers also used the travel time to detect the most critical links in a highway network [121, 137], which give insightful information on the impacts of a probable disruption scenario and develop strategies and recovery plan according to the link importance ranking. Besides, travel time can be interpreted in different forms to explain the transportation system's resilience characteristics. For example, Donovan and Work [41] used pace (travel time per mile), the normalized version of travel time as the parameter to identify link/network performance before and after the disaster, which provides a logical way to measure the post-disaster performance of the system using NYC taxi data without any other field data collection. However, if a system goes through large-scale destruction that affects most links and requires a long recovery period, the pace may fail to provide a comprehensive overview of network status. Several studies considered minimization of travel time in disaster scenarios with a varied range of impact [83,90], without including the impact of pre-disaster preparedness activities. In addition to considering "travel time" as a resilience index, several researchers have developed other metrics using travel time data (e.g., vulnerability, reliability, and restoration), which are discussed separately in the following sections.

\section{Reliability}

Reliability is typically defined as the probability of being functional/operational in post-disaster time [12]. From a transportation system perspective, it can be the performance of the system with a certain level of service under disruption scenario [91]. Reliability can also be interpreted as the probability of successful completion of trips between Origin-Destination (O-D) pairs. Uncertainty in the disaster impact influence the travel demand and behavior and thus influence travel reliability. Based on the literature, reliability can be classified into three categories.

(i) Connectivity reliability represents the probability of maintaining connectivity between O-D pairs in times of disaster [32, 42, 91]. An O-D pair is considered to be connected if there is at least one connected path/route available between that O-D pair. However, connectivity reliability fails to explain the efficiency of the connected route in terms of capacity or operability. It considers that the failure of one link does not impact the functionality of other links, which is unrealistic as disasters often impact many links at a different level of performance degradation [42]. Reduction in traffic flow is a common disaster impact, which is neglected in the connectivity reliability concept [32].

(ii) Travel time reliability concept uses travel time to estimate the transportation network's service level. 
This concept considers users' trip making decision and how disasters influence this decision making [56, 61, 92]. Fu and Lam [56] and Liu et al. [92], both modeled a transit-based transportation performance improvement for joint-activity travel pattern, and park\&ride, respectively. However, the application of the model was limited to homogenous groups (same activity patterns), which dictates their similar travel behavior of trip makers [56]. Further, Yin and Leda [137] analyzed the drivers' route choice pattern in an after-disaster scenario. With frequent travel time fluctuations, the disutility of commuters (i.e., the chances of not choosing a particular route by users) was greater. Noland and Polak [106] included departure time choice behavior with the route choice pattern of the drivers to measure travel time variability. As travel time reliability considers the variation of travel choice patterns for different disaster situations, this can be a reliable measure to evaluate transportation system performance under disaster scenarios.

(iii) Capacity reliability is defined as the probability of a certain demand can be accommodated with the desired level of service. Unlike travel time reliability, this concept does not incorporate the travelers' trip decision, and change in behavior patterns during/ after a disaster event, which are crucial factors in evaluating system resilience. Capacity reliability was first presented by [31]. They analyzed the supply side (i.e., systems capacity) of the transportation system and showed that the redundancy capacity of a transportation network could reduce the disaster consequences.

\section{Vulnerability index}

Vulnerability is used extensively to express the susceptibility of the critical components of a transportation network, and commonly represents the operational performance of the network [16, 77, 96]. Mattsson and Jenelius [96] introduced conditional vulnerability concepts that can be represented as the cumulative or aggregated consequences (in terms of damage to system functionality) due to any disruption scenarios. Furthur, Latora and Marchiori [87] measured vulnerability priority by the performance reduction of the infrastructure system, and the vulnerability index was measured as the percentage of performance drop due to the impact of different level of damages. Vulnerability and reliability indices provide complementary measures of a network. Vulnerability considers potential loss or degradation, whereas reliability considers the remaining functionality of the transportation systems. Similar to the travel time index, vulnerability index can be used to identify the criticality of infrastructure components (e.g., road links) using probabilistic disruption scenarios to measure the resilience of the transportation system [43, 81, 86]. Several other metrics were proposed based on the vulnerability concept, such as link-level capacity [84], the largest connected component during a disaster [87]. While link-level capacity estimation is more efficient in the small-network (e.g., intra-city transportation network), the largest connected component concept is more efficient in the large-network (e.g., inter-city transportation network). Several studies (for example, [43, 77, 84]) investigated the vulnerability assessment of a road transportation network by identifying the impact of important links in the network. In these studies, the system performance attributes such as traffic flow, network/link capacity, travel time, and alternate routes were considered. Murray-Tuite and Mahmassani [103] proposed a combination of a vulnerability index and a disruption index to determine the importance of a link for a particular O-D connectivity. Generally, the links used by most O-D pairs in the network were considered to be most important. One of the most recent works on vulnerability analysis considered the combined effect of flood and blackouts and evaluated the impacts on different critical infrastructures, including road infrastructure [49].

\section{Restoration time}

Post-disaster transportation system restoration possesses a great significance in disaster response and management. The objective of transportation agencies is to restore blocked/damaged/failed links in the road network after any disaster so that the relief distribution and post-disaster evacuation program can be operated efficiently. Based on this concept, $\mathrm{Hu}$ [71] developed an optimization-based model to maximize the number of restored paths in the least time. Ariano and Pranzo [7] adopted a system restoration model for railway based on minimizing the delay among the consecutive train trips. The efficiency of restoration time-based models depends greatly on the emergency resource dispatch operation $[57,79]$.

\section{Travel demand}

Chen and Miller-Hooks [99] defined resilience as the expected fraction of travel demand (before a disaster) the transportation system can accommodate post-disaster (after the recovery works are completed), considering the allocated recovery budget. Measurement of reliability based on the road network link's capacity to serve a specific travel demand was considered as a resilience index as well in Chen et al. [32] and Patil and Bhavathrathan [111]. One of the key limitations of these studies is that they rely on the assumption of certain roadway capacity distribution rather than estimating the distribution using 
field data. Also, these studies demonstrated the relationship between resilience and reliability, as researchers often provided a loose interpretation to distinguish these two.

\section{Cost or budget}

Many researchers emphasized the cost related to the system disruption, which may include operating cost (e.g., travel time cost, fuel cost), restoration cost, traffic delay cost. For instance, Li et al. [88] proposed the use of vehicle cost (i.e., travel and idle time cost) and delay cost (i.e., delay related to assigning the backup trips) to solve the bus rescheduling problems due to any disruption. Similarly, Kliewer et al. [83] solved bus scheduling problems based on the operating cost (deadhead trip cost) minimization. Kliewer et al. [83] considered a multipledepot scenario (i.e., multiple depots (nodes) for passenger pick-up and drop-off locations), where $\mathrm{Li}$ et al. [88] considered a single-depot scenario. Asadabadi and Miller-Hooks [10] used operating cost as a requirement of relative investment to increase the resilience performance in a maritime-based transportation network system. Several studies replaced the concept of cost by the concept of recovery budget [8-10,33]. Recovery budget and cost are related to post-disaster time. Recovery budget does not necessarily mean the budget needed to recover from the disruption impact completely; rather, it represents the budget that can be allotted for recovery activities based on the economic situation of the community/ agency. The discrepancy between the recovery budget needed and the recovery budget allotted can vary depending on the costs of damage associated with disruption impact. However, allocating additional investment to improve existing infrastructure's condition in predisaster time considering stochastic climatic events can reduce the requirement of a high recovery budget postdisaster $[8,9]$.

\section{Capacity}

The capacity of a system to sustain from the impacts of a disaster, sometimes known as adaptive capacity, can be defined as how long a system can survive on its own after the occurrence of any disruptive event. Flow capacity, a core system property, is used as a key parameter in resilience analysis to analyze the sustainability of a system [19]. This parameter could take any value from zero (for the worst state of the system due to disaster impact) to any reasonable maximum (based on the disaster impact severity). A two-space genetic algorithm was used, and network resilience was calculated as a normalized difference between the system operation cost in the worst state and reasonably recovered state [19]. Yoo and Yeo [138] used adaptive capacity represented as the ratio between the margin of the remaining functional nodes of the network in post-disaster and the number of nodes before the disaster. This research identified the susceptible nodes for degrading adaptability performance. In Sultania et al. [119], the most probable state (MPS) model was developed to quantify risk (the threat of a disaster) associated with the occurrence probability of disruption and the resulting consequences. Chen and Miller-Hooks [33] formulated a capacity indicator to quantify network resilience by considering the network's inherent ability or adaptive capacity to cope with the impact of disruptions [33]. In general, proactive and protective measures to improve the system resilience are beneficial in reducing disaster consequences; Chen and MillerHooks [99] argued that reactive actions could be more beneficial. Besides, in air transportation network-based resilience studies, the taxiway capacity and runway capacity during and after disaster phases are considered as resilience parameters (for example, $[47,75])$. Janic [75] measured airport resilience based on the number of flights accommodated at the airport for a specified capacity ratio, while Faturechi et al. [47] quantified the expected probability to accommodate the number of flights in a post-disaster situation. Expressing the system resilience as the ratio of the percentage of the number of trips that can be accommodated in a post-disaster scenario, Ahmed et al. [5] proposed a simplified model to evaluate transportation system resilience which considered a mixed-traffic scenario of connected and automated vehicles (CAVs) and manual vehicles. Another recent article considered the arising travel demand from emergency evacuations out of disaster impacted zones and optimally solved to find the efficient routing strategy to improve the evacuation operation [139].

\section{Accessibility index}

The accessibility index is used to measure the accessibility of network-level O-D combinations in terms of trip making, which is a relatively less explored index in evaluating the resilient performance of a transportation network. Sohn [117] and Chang [30] proposed the accessibility index as a medium to determine the relative importance of highway links due to the impacts of disaster events. While Sohn [117] used accessibility as a system parameter to measure performance to emphasize the retrofit (recovery of roads/links from damage) priority, Chang [30] used accessibility index to evaluate the restoration process where higher accessibility index represents more network links are restored. In these studies, the distance between different counties (i.e., Maryland road network system), traffic volume, and total 
populations of the counties were used to measure the accessibility index parameter.

\section{Shortest path}

The shortest path is another less frequently used index in resilience studies. As the availability of multiple routes for an O-D combination is important to maintain redundancy or contingency, the shortest path parameter is used to measure the most efficient route. For example, Duque and Sorensen, Adjetey-Bahun et al. [3], and Adjetey-Bahun et al. [4] have identified the shortest path in a network to quantify the alternative routes in case of post-disaster routing. Shortest path identification can be useful to allocate resources to repair a road network after a disaster. Adjetey-Bahun et al. [3] and AdjeteyBahun et al. [4] proposed models to measure railway transportation system resilience. Adjetey-Bahun et al. [3] considered passenger flow only in a network of 360 stations and 18 lines, whereas Adjetey-Bahun et al. [4] considered a more complex network system with more connected sub-systems such as power and telecommunication.

\section{Resilience triangle}

The resilience triangle is a unique index and was first proposed in Berdica [16]. It is a graphical representation of resilience in which a combination of three parameters was considered: the performance loss of the system, time to reach the lowest level of performance, and recovery time. In general, this index does not represent the real state of damage; rather, this indicates a qualitative status in terms of capacity reduction and travel time. Later, researchers have explored this concept to develop the resilience improvement strategy [2]. In this work, the angles of a resilience triangle indicated the system performance loss, the duration to reach the poorest performance state, and the duration to recover [2].

As explained in this section, Resilience indices were measured by considering one factor (e.g., travel time) to multiple factors (e.g., the reliability index is measured by travel time, capacity, and flow). Table 1 summarizes the factors considered in the quantification of each resilience index.

\section{Transportation mode based models}

Disturbance in the transportation services due to disruptions (e.g., extreme weather, terrorist events) causes partial or full impairment of network links, interruption of scheduled trips, trip delay, or trip cancellation. Many studies explored mode-specific resilience modeling considering critical factors associated with different transportation modes. This section reviewed mode-based resilience modeling for different modes.
Table 1 Factors considered in the quantification of a resilience index

\begin{tabular}{ll}
\hline Resilience Quantification & Factors \\
\hline Resilience Index & (i) Travel time \\
Travel time & (ii) Pace \\
Reliability & (i) Travel time \\
& (ii) Capacity \\
Vulnerability & (iii) Flow \\
& (i) Travel time \\
(ii) Capacity & (iii) Flow \\
Restoration time & (iv) Large connected component \\
(i) Restoration time \\
(ii) Delay \\
(i) Travel demand demand \\
(ii) Flow \\
(i) Recovery budget \\
(ii) Delay cost \\
(iii) Operating cost \\
(iv) Damage cost \\
(i) Capacity \\
(ii) Flow \\
(iii) Travel demand \\
(i) Connected link \\
(ii) Flow \\
(iii) Distance \\
(i) Link distance \\
(i) Recovery time \\
(ii) Time to reach worst state \\
(iii) Recovery budget
\end{tabular}

\section{Roadway transportation}

While discussing resilience modeling for roadway transportation, works can be subdivided into different modes: public transit (e.g., bus) system, passenger car transportation system, and freight transportation system.

\section{Public transit mode}

Disruptive events such as extreme weather, massive accidents, or vehicle breakdowns can disrupt the regular transit vehicle scheduling process. Researchers proposed models for the transit rescheduling process so that the impacts of disruptions (disturbance in the scheduling of transit service operation) could be rescheduled in realtime. Depending upon the extent of disruptions, the rescheduling process may take more or less time to adjust the performance of the affected transit system. Bunte and Kliewer [27] reviewed the models related to vehicle 
scheduling problems (VSP) in terms of a single depot case and multiple depot case. Single depot case was analyzed by formulating Minimal decomposition model [21, 115], Assignment model [67, 109], Transportation model [55, 116], and Network flow model [17, 39]. Minimal decomposition model was only effective in solving for minimum fleet size (to accommodate a certain trip demand), but could not explain the variation in optimum operational cost (for different fleet sizes). The assignment model considered operational costs. Freling et al. [55] and Silva et al. [116] demonstrated the necessity of optimizing the vehicle scheduling problem by maximizing the number of vehicles. In general, considering variation in the operation costs (i.e., fixed and variable) and the size of the fleet, the output of the analysis of vehicle scheduling problems using different models could deviate from each other [27]. Depending on the number of nodes per depot, constraints in the problem formulation, and the size of the fleet, multiple depot case has been discussed in the perspective of Single-Commodity models [29, 52, 53], Multi-Commodity models, and set partitioning models $[27,62,110]$.

The increasing frequency of disruptive events creates the necessity of automated rescheduling techniques to assist the decision-making process. Li et al. [88] developed an efficient solution approach using a parallel auction algorithm. Parallel auction algorithm computationally efficient in determining the schedule with the minimal operating cost (i.e., travel time and idle time cost) and delay cost. However, in the case of small problems (for example, 100 disrupted trips), this algorithm performs similar to any other algorithms. According to [93], the most familiar model for the VSP is the connection-based network (CBN) model [54, 63, 94]. In the CBN model, the trip location (origin and destination) and depots were considered as nodes, and the possible connections/routes were developed between these nodes. In this approach, the vehicle cost was reduced by $10 \%$ on average to reschedule the disrupted trips. However, this approach is not efficient for a large number of disrupted trips as the number of rescheduling vehicles, and the availability of alternate routes become insufficient. Later on, the Timespace network (TSN) based model [59, 82] was introduced for VSP to address the complexity of a higher number of trips, in [83]. In general, TSN was used in the airline rescheduling problem. TSN model reduced the number of variables in the exact optimization model. As multiple disruptions could affect a system simultaneously, dynamic vehicle rescheduling problem (DVRSP) approach can be more beneficial considering the simultaneous effect of multiple disruptions [38]. Figure 2 illustrated the classification of the studies reviewed in the context of multidepot and single depot problems.

\section{Passenger Car mode}

After any disruptive events, recovering from the damage and impact of disruptions becomes critical to maintaining the accessibility at its desirable level. To ensure accessibility after any disaster, Duque and Sorensen proposed a formulation based on the Greedy Randomized Adaptive Search Procedure (GRASP) metaheuristic, in which an insertion algorithm was used. In the GRASP metaheuristic,

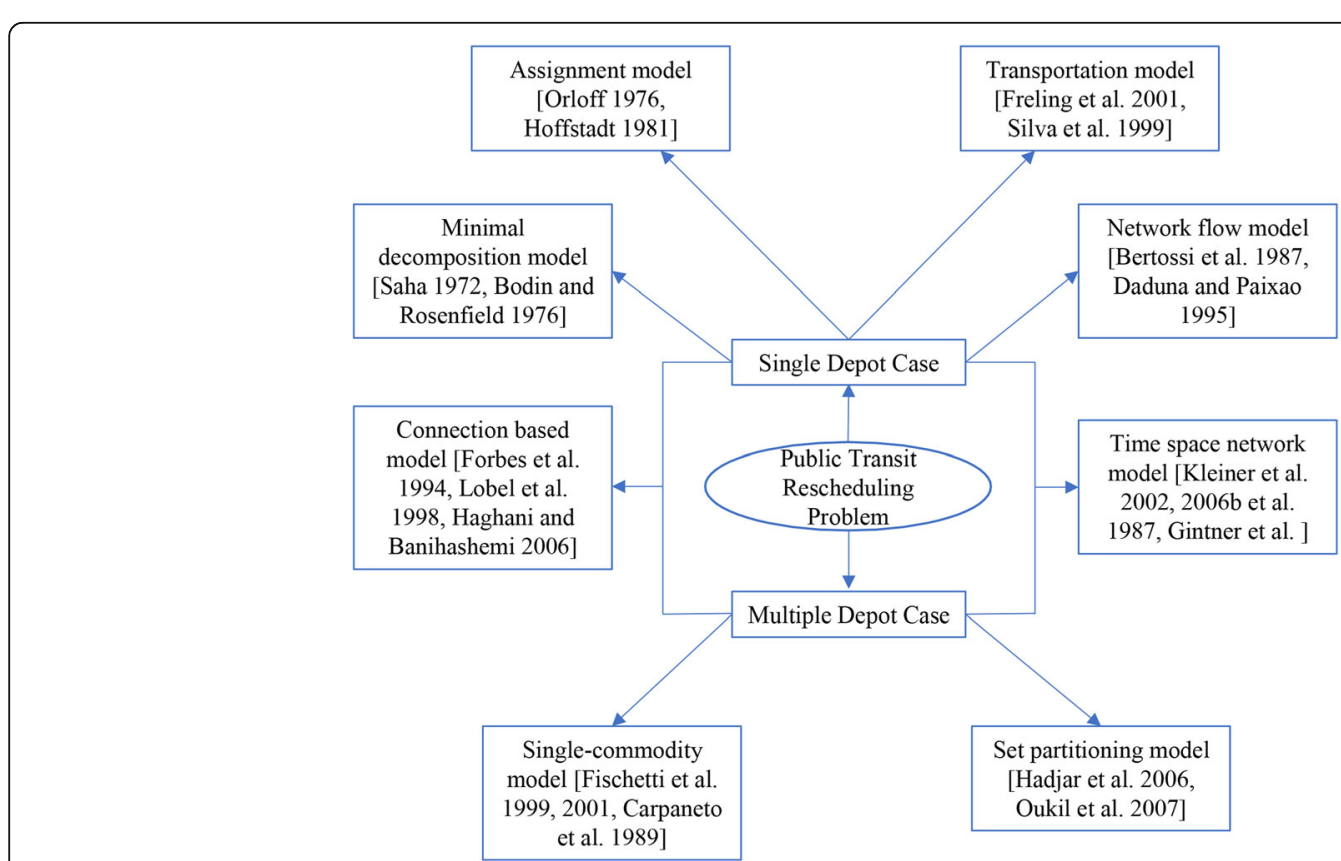

Fig. 2 Categorized reviewed articles in single and multiple depot scenario 
the algorithm was modified to select a random road to repair from a restricted candidate list (RCL). Variable Neighborhood Search (VNS) metaheuristic was also an integral part of the methodology, which was a type of variable neighborhood descent (VND) algorithm described in [65]. This approach is beneficial to allocate resources for the repair of road networks based on their influence in improving accessibility.

Similarly, in Sohn [117], an accessibility index is determined for highway network links and demonstrated for a highway network in Maryland under a flood disaster scenario. The critical links identified by considering distance as the criterion appeared different than the critical links identified considering the distance and traffic volume as the criteria. However, local road networks and the time for recovery work were not considered in the study to address the complexity of the network model. Most vital node (MVN) or most vital edge (MVE) was used to identify the node or edge whose removal caused the maximum degradation of the network performance [121]. To measure the deterioration of the network performance, the authors observed the travel time variation due to the removal of links and nodes. The total number of impacted links increased with demand. The medium demand scenario compared to the high demand scenario observed more reduction in speeds since the network in high demand case was already congested. As postdisaster road restoration model was crucial in planning for relief distribution in the after-disaster response phase, a time augmented network flow model was proposed in which trips of working groups (the groups that work to restore roads) and relief flows were distributed according to demand (which region needs the most restoration work) with the goal of minimizing restoration operation time [136]. Moreover, a dynamic path based mathematical restoration model was proposed in Aksu and Ozdamar [6] to address the issue of restoring blocked links in after disaster scenarios with more efficient and smart effort considering limited resources. While the heuristic proposed in Yan and Shih [136] took about 33 min to solve the 17 problem instances with an error gap of $2.82 \%$, the model of Aksu and Ozdamar [6] showed optimality gap (error gap) of about $0.05 \%$. Because of less error possibility and tendency to perform faster iterations, [6]) can be the more efficient model.

\section{Highway based freight transportation}

As reliable delivery is critical in freight transportation, rapid restoration and recovery of the freight supply chain after a disaster is paramount. Adams et al. [2] proposed modified resilience triangles (discussed earlier in section 4.10) to measure the resilience of a freight supply chain. This study considered data from sampled truck speeds and counts along the interstate 90/94 corridor from Hudson to Beloit in Wisconsin, USA. This study was a unique attempt to use resilience triangles in interstate freight operations, which is a practical approach in evaluating disaster performance and impacts. Multiple strategic approaches such as column generation, Benders decomposition, and Monte Carlo simulation were integrated to develop a stochastic, mixed-integer program planning [33]. The model showed an average improvement in the resilience by $57 \%$, which ranges from $10 \%$ to $141 \%$ for different tested disaster scenarios. As freight plays a key role in emergency relief distribution during and after a disaster, the affinity network model or cooperative fuzzy optimization approach was considered to improve the performance of emergency freight mobility in disaster management $[71,140]$. These models demonstrated the optimum path selection to operate the relief work efficiently. Depending on the disaster damage level and affected area size, the damage to the infrastructure and the number of affected fleet size could be significantly larger, which may become difficult to simulate and solve computationally for the porposed models. Thus, most of the proposed models find it difficult to address the large fleet size problem efficiently [33, 71]. Vugrin et al. [132] developed a resilience model based on the operating cost requirement in disaster scenarios and applied the model on a transportation system used for the petrochemical industry product supply. Two main components of system resilience (i.e., systematic impact (SI) and total recovery effort (TRE)) were calculated to determine the impacts of disruptions. SI refers to the difference between the actual system performance and the targeted system performance, and TRE refers to the efficiency of the recovery activities during the postdisaster time. In this research, two category 2 hurricane scenarios were considered for two case study sitesHouston, Texas, and New Orleans, Louisiana. The analysis showed that the transportation system used for the petrochemical industry product supply was more resilient in New Orleans than the Houston, which critically demonstrated the importance of having redundancy in the network system operation in terms of availability of alternate routes.

\section{Railway transportation}

This section presents resilience models related to the commuter rail system. Addressing the disturbance in train scheduling due to disasters, Garcia et al. [58] proposed an optimization schema to address vehicle rescheduling problems (VRSP), a dynamic version of VSP, which had three components: (i) a predictive simulation model, (ii) a queue system, and (iii) a constructive heuristic algorithm. Rather than relying on human experts, this heuristic algorithm supported the decision support tool through which reassignments of trips were made 
from numerous possible alternatives (e.g., selecting the best route from multiple routes). Quantifying the resilience of a railway transportation system was beneficial to identify resilience indicators and planning. Several models were proposed, such as a time-dependent simulation model [3] to quantify resilience indicators and asynchronous approach based on blocking times [74] to identify and resolve remote conflicts. While real-time dispatching system approach, known as ROMA (Railway traffic Optimization by Means of Alternative graphs) was proposed in Ariano and Pranzo [7] to automatically recover from disturbances, event-based integer programming (IP) model was proposed in Fekete et al. [48] which was capable of shifting and canceling trips as well as modifying vehicle schedules. Among these models, the event-based IP model performed more efficiently as this model could address multiple types of perturbation scenarios. Adjetey-Bahun et al. [4] measured the resilience of a mass rail system applying a simulation-based model and considered passenger delay and passenger load as a system's performance indicators. The crisis management plan in Adjetey-Bahun et al. [4] had three components: absorption (accounts for passenger waiting time beyond a certain threshold), adaptation (represents starting of temporary train services on some part of the affected railway line to serve passengers), and recovery (time to recover the damage condition of the impacted railway station and gain back the pre-disaster performance level). It could be concluded that an efficient recovery plan had a higher impact on resilience compared to the absorption and adaptation plan. In some instances, to improve the resiliency of the metro rail network, integration of other modes such as bus services were proposed [78]. According to Jin et al. [78], by integrating the localized bus system with a metro system, the resilience can be improved by an additional $58 \%$ compared to the resilience value without any integration. Future researchers should focus more on this type of synchronized operation of multiple modes. Man-made disaster like terrorist attacks often targeted transit system, and studies analyzed the impacts of terrorist attacks [37, 97] in transit system. In Cox et al. [37], the direct static economic resilience (DSER) concept was used to calculate maximum economic disruption a terrorist attack could cause to a transit system. Few major resilience assessment guidelines were developed in this research, such as the Functional Resonance Analysis Method (FRAM) concept and the Resilience Analysis Grid (RAG). The rationale of these resilience guidelines was to develop an advanced resilience management plan for the metro network system.

In general, evacuation is one of the key components in the disaster management process and system resilience. As a commuter rail system is capable of carrying large groups of people during an evacuation, the wellcoordinated performance of the commuter rail system is critical during evacuation. No study has explored the idea of incorporating the performance of the commuter rail system in evacuation time, and this can be a future research topic.

\section{Airway transportation}

Airway transportation is one of the most sophisticated transportation systems. Disruptions in airway transportation can happen due to natural disasters (e.g., snowstorm), power failure, failure of pavement structure or management disruptions (e.g., IT infrastructure failure) in air services.

Due to the different meteorological scenarios, the condition of airport pavements could lead to the partial or complete shutdown of an airport. To assess the resilience of an airport's pavement (i.e., runway and taxiway) network, a stochastic integer program based on the integer L-shaped decomposition was proposed [47]. This study can be considered as one of the most comprehensive analyses of airport resilience phenomenon due to pavement failure. The maximum flow rate (number of takeoffs and landings) was used in this study to assess performance metrics. Under normal weather conditions, the model was able to produce a maximum flow rate of 64 maneuvers per hour. With the increment of recovery budget, the performance metrics increased significantly after disaster scenarios [47].

Ground holding technique is an old concept that has been proposed in $[130,131]$ to model airport runway operations. In the ground holding technique, the time needed for each aircraft to be held on the ground before takeoff was considered, and researchers developed approaches to minimize the time wasted before takeoff to reduce the delay cost. However, the ground holding technique could not handle any disruptions. In Filar et al. [51], an adaptive optimization model was proposed by incorporating special decision features to improve airway transportation performance, such as night curfew from 11.00 p.m. to 6.00 a.m. This study was a good representation of how managerial decisions can impact the operation performance.

Crew absences, mechanical failures, and bad weather are some of the major causes that hamper the performance of airlines [23]. The integrated recovery approach considering aircraft, crew, and passengers was proposed in several studies $[1,23,34,85]$ to overcome these issues. According to Bratu and Barnhart [23], the proposed simulation-based decision support tool, disrupted passenger metric (DPM) model, was able to reduce the count of disrupted passengers by $63.1 \%$ and the delay experienced by these passengers by $15.9 \%$ for disruptive scenarios (e.g., crew absences, mechanical failures, or 
bad weather). In general, airports are considered as a single source point that contributes to a huge amount of flow or trip and differnet disruption scenarios can be developed for high traffic volume. Thus, a simulationbased decision support tool can be beneficial in airport resilience quantification.

Man-made disasters can impact the airway transportation system operation greatly. For example, after the 9/11 terrorist attack, air travel demand reduced significantly for several months. Several new security policies such as baggage screening and the federal passenger screening were implemented, and studies analyzed the impacts of these security measures on air travel demand $[20,35]$. According to Blalock et al. [20], federal screening of passengers had little effect on passenger volume.

\section{Waterway transportation}

The impacts of disruptive events in waterway transportation were not widely explored in the existing literatures. The performance of the waterway based transportation network system was explored in past studies for the operation management problems. Rescheduling in linear shipping is one of the recommended approaches discussed in most of the studies reviewed in this research.

Effective approaches for disruptions in linear shipping were under-explored. Few recent works on rescheduling problems in linear shipping are $[24,89]$. Brouer et al. [24] formulated a mathematical model to address the vessel schedule recovery problem (VSRP) and a decision support tool to reduce delay in a linear shipping network. Speed adjustment, omitting port calls, or swapping port calls were the three recovery modes to recover the scheduling problems due to disruptions [24]. The model was able to generate an improved routing strategy for different disruption scenarios in $5 \mathrm{~s}$. Waterway based network resilience quantification is always tricky as waterway based disasters (for example, typhoon or hurricane) often change their trajectory over time, and to incorporate this aspect in the model is complex. According to Li et al. [89], the random nature of the typhoon behavior during the formation and evolution process significantly impacts the decision-making process for any vessels heading to a port. Either they speed up to reach port before the typhoon, or they slow down to reach port after the typhoon. In Vernimmen et al. [128], different practical causes (e.g., bad weather at sea, congestion, labor strikes, fire incidents, ship collisions or ship groundings) behind the schedule instability were analyzed. Qi [112] proposed two models, one for a single vessel and another for multiple vessels. The model for a single vessel focused on the decision-making process during the time of crisis, whereas the model for multiple vessels aids in solving the rescheduling of multiple vessels considering the practical scenarios. Disruptions had greater chances to affect the operation of multiple ports and multiple vessel network systems. Most studies (for example, [24, 89, 112]) considered a known incoming disruption in evaluating operational strategies. But the uncertainty of disruptions has a drastic effect on scheduling optimization in linear shipping. Thus, the randomness of disruptive events should be considered in resilience planning.

\section{Models based on the analysis technique}

In this section, all the reviewed articles are subdivided into two subsections based on analysis technique- (i) step-wise assessment models, and (ii) optimization-based models.

\section{Step-wise assessment models}

Step-wise assessment models can be classified into two cateogies- qualitative assessment models (discussed in Section 6.1.1), and simulation based models (discussed in Section 6.1.2).

\section{Qualitative assessment models}

Qualitative resilience assessment models typically establish qualitative performance criteria $[25,26,66$, 107]. For instance, Bruneau et al. [25] developed a framework to assess the impact of seismic events on community resilience, considering the following three evaluation criteria; (i) failure probabilities of the system, (ii) consequences from failures, and (iii) recovery time. According to Bruneau et al. [25], a resilient system should demonstrate following four properties; (a) Robustness, (b) Redundancy, (c) Resourcefulness, and (d) Rapidity. A comprehensive framework was developed to define seismic resilience and the impact on infrastructure (for example, buildings) and community [26]. discussed the effects of a seismic event on the transportation network and proposed a risk mitigation strategy to enhance resilience. In this work, a systematic risk assessment and management approach was developed using a Geographical Information System (GIS) to facilitate the illustration of the risk information for a road network. Heaslip et al. [66] presented a framework for estimating the magnitude of societal and economic impacts of disasters. Though this research presented a different perspective by evaluating societal and economic impacts, the transportation system impacts were not considered in the framework and can not be used by transportation agencies who are responsible for maintaining the system. Omer et al. [107] proposed a travel time resilience assessment model. Applying the model on the road network between Boston and New York, the roadway link connecting Hartford and New York City was found to be 
the weakest route in terms of travel time resiliency, which implied the criticality of this route compared to other routes in the network. This model was applied to a large network (inter-city transportation system) and is a good example in capturing the regional impacts of major disasters. However, the applicability of this model in a small network system was not explored yet as travel time can be misleading in explaining the performance of a small network. In general, long-distance routes (which is common in inter-city or large network system) show a significant change in travel time during disaster then shortdistance routes (i.e., small-network system).

Some studies divided the freight system resilience plan into several stages, such as the identification phase, assessment phase, implementation phase [28, $60,98]$. The identification phase deals with selecting the objectives of the resilience plan and identifying the key contributing factors. The assessment phase involves determining the current state of the system through vulnerability assessment, public/private collaboration mechanism, and assessing the requirements for regulatory and policy needs. Finally, the implementation phase includes implementing the plan with a large-scale simulation. These studies explored the policy-related scenarios or improvement strategies that a community can undertake in their resilience plan. Reliance on vulnerability assessment in these studies is important and effective. However, there are many contributing factors (other than vulnerability) that can play a significant role in resilience improvement. To address some of these limitations, Reggiani [113] considered the number of connected components with vulnerability in the resilience quantification process. The comprehensive system approaches to monitor and evaluate the emerging scenarios (i.e., new configurations of the topological connection of the network) for various scales of networks were discussed in detail for the impact of targeted attacks.

\section{Simulation-based models}

As quantification of resilience is a complex process, simulation-based modeling process provide an alternative approach. Researchers used established traffic assessment tools (e.g., DYNASMART-P) to analyze the traffic scenarios in resilience model development. Transportation resilience can be defined in ten dimensions [100], and this article evaluated four dimensions- adaptability, mobility, safety, and the ability to recover. Factors considered in the prioritization of these four dimensions over the six remaining was not clearly explained. The optimal user equilibrium traffic assignments using the traffic assignment-simulation tool DYNASMART-P was used in this study. Adaptability was defined as the availability of infrastructural elements for special use, such as allocating lanes for high occupancy vehicles. Adaptability was calculated using Eq. 1.

$$
m_{1}=\frac{\sum_{w} \theta^{r s} \phi_{p} p_{w}^{r s}}{\sum_{w} \theta^{r s} p_{w}^{r s}} \times 100
$$

Where, $p_{w}^{r s}$ is the route of vehicle $w$ from origin node $r$ to destination node $s, \phi_{p}$ is a binary variable ( 1 if route $p$ contains one or more special use lanes such as high occupancy vehicle lane, and 0 otherwise), $\theta^{r s}$ is a binary variable ( 1 if a route exists between origin node $r$ and destination node $s$ with a special use lane, and 0 otherwise).

As the risk profile of a transportation network is critical to analyze the resilience performance, Murray-Tuite [101] proposed a combination of event tree-based approach that was introduced in Murray-Tuite [102]. Monte Carlo simulation was applied to determine the risk profile of a hypothetical transport network in the case of a terrorist attack. A hypothetical city was used in the simulation, which consisted of 25 potential targets for a terrorist attack, a transportation network of 26 nodes, and 75 links. This exemplary network system was helpful in demonstrating the methodology and can be transferrable to a real-world network using local data or estimates.

Adjetey-Bahun et al. [3] proposed a simulation-based quantification approach to measure the resilience of a railway system for an external perturbation scenario. The performance indicators used in this study were the cumulative count of passengers that reach their destination and the total delay of the passengers after the perturbation scenario. This study used Eq. 2 to quantify the performance indicator at a particular station. A crisis management plan was incorporated into this model. It was found that an efficient crisis management plan was able to significantly reduce the impacts of perturbation scenarios on the system [3].

$$
P_{s}(t)=1-\frac{\alpha_{s, d}(t)-\alpha_{s}(t)}{L_{s}(t)-\alpha_{s}(t)}
$$

Where, $P_{s}(t)$ is defined as the performance indicator at station $s$ at time $t, L_{s}(t)$ is the passenger load at station $s$, $\alpha_{s, d}(t)$ is the passenger load at station $s$ during the perturbation, and $\alpha_{s}(t)$ is the passenger load at station $s$ during normal operation of the system.

A combination of the integer L-shaped method and the Monte Carlo simulation was used to measure the maximum and minimum resources requirement of a freight transportation network system to improve resilience [99]. The comprehensive nature of this article was 
unique, which includes the impact of preparedness activities in the pre-disaster phase and post-disaster phase resilience quantification based on key factors such as capacity, flow, recovery time, and budget. Capacity was represented as the network traffic accommodation capacity in the post-disaster scenario compared to the predisaster original network traffic demand applying the following eq. 3. A double-stack container network system in the western US was used to demonstrate the application of the model. It was concluded that recovery efforts and preparedness activities could improve resilience level by $14 \%$ and $11 \%$, respectively, where Recovery and preparedness together could improve resilience by $18 \%$.

$$
\begin{aligned}
\alpha & =E\left(\frac{\sum_{w \epsilon W} d_{w}}{\sum_{w \epsilon W} D_{w}}\right) \\
& =\left(\frac{1}{\sum_{w \epsilon W} D_{w}}\right) E\left(\sum_{w \epsilon W} d_{w}\right)
\end{aligned}
$$

Where, $D_{w}$ is the original pre-disaster demand for OD pair $w$ and $d_{w}$ is the post-disaster maximum demand that can be supported by the network for O-D pair $w$.

Hurricane Sandy's impacts and post-event recovery pattern in the transportation industry was a key topic for many literatures after 2012. Several recent studies developed novel techniques using real-world data from hurricane Sandy. For example, Zhu et al. [141] proposed a recovery model to find out the spatial correlation of recovery patterns in New York City after hurricanes Irene and Sandy using taxi and subway ridership data using loss-of-resilience (LoR) parameter (Eq. 4). The model demonstrated that the critical model parameters, $\alpha, H$, and $L o R$ varied greatly by individual storm, transport modes, and spatial locations.

$$
L o R=\int_{t_{0}}^{t_{1}}\left[1-\frac{1}{1+e^{-\alpha(t-H)}}\right] d t
$$

Where LoR is the loss-of-resilience from the time of the original hurricane impact, $\alpha$ represents the factor affecting the slope of recovery rate, and $H$ is half of the recovery time.

Donovan and Work [41] modeled the impacts of Hurricane Sandy in New York city using 700 million taxi trips' GPS data to empirically quantify resilience considering the variation between the values of pace (travel time per mile for any two locations) of different regions. Equation 5 was used to calculate the weighted average of the individual trip paces in this study. This analysis showed that taxi GPS data could be a low-cost alternative data in evaluating the effects of disruptive events on transportation infrastructure. Their analysis showed that about 2 min of delay per mile was caused by Hurricane Sandy and this spike in delay originally occurred 2 days after the hurricane attack [41].

$$
P(i, j, t)=\frac{\sum_{r \epsilon T_{i, j, t}} u(r)}{\sum_{r \epsilon T_{i, j, t}} l(r)}=\frac{\sum_{r \epsilon T_{i, j, t}} l(r) \frac{u(r)}{l(r)}}{\sum_{r \epsilon T_{i, j, t}} l(r)}=\frac{\sum_{r \epsilon T_{i, j, t}} l(r) p(r)}{\sum_{r \epsilon T_{i, j, t}} l(r)}
$$

Where $u(r)$ is the travel time, $l(r)$ is the metered length, and $p(r)$ is the pace of trip $r$.

While evaluating the resilience metrics, some studies considered the critical interdependency of the system with other systems (e.g., energy system). For instance, an energy and transportation investment multi-objective evolutionary algorithm, which was initially proposed by Ibanez and McCalley [72], was used to optimize the performance strategy of energy and transportation systems based on three criteria- cost, sustainability, and resilience [73]. The proposed resilience formulation could be used to design long-term investment plans for interdependent infrastructures.

Janic [75] formulated a model to estimate the resilience, friability (i.e., rate of decreasing resilience), and costs of the air transportation network. This model included different airports' relative importance, airport selfexcluding importance, airport resilience, and air transport network resilience. Equations 6 to 9 were used to measure the relative importance, self-excluding importance, and resilience of each airport, respectively. Equation 6 measured the relative importance of an airport by calculating the ratio of the number of flights (both landing and takeoff) handled by an airport compared to the total number of flights handled by all airports. Equation 7 measured the self-excluding importance of an airport by omitting the number of flights handled by an airport from the denominator of eq. 6 to represent the impact of removing a specific airport from the network. Equation 8 measured the resilience of an airport by considering the amount of incoming and outgoing flights during and after a disaster, and eq. 9 estimated the resilience of the airport network as the summation of the individual airport's resilience. A network of 16 airports was analyzed in this study to evaluate their resilience due to Hurricane Sandy. Based on the analysis results, the disaster impact was the most severe impact (i.e., the lowest resilience) on the fifth day of the disaster due to the closure of multiple airports. This work was a simplistic representation of an air transportation system in disaster times and was able to express realworld implications of disasters.

$$
w_{i}^{y_{i}}(\tau)=\frac{u_{i}^{y_{i}}(\tau)}{\sum_{j=1}^{N} u_{j}^{y_{j}}(\tau)}
$$




$$
\begin{aligned}
& v_{i}^{y_{i}}(\tau)=\frac{u_{i}^{y_{i}}(\tau)}{\sum_{j=1 / j \neq i}^{N} u_{j}^{y_{j}}(\tau)-u_{i}^{y_{i}}(\tau)} \\
& R_{i}^{y_{i}}(\tau)=\sum_{j=1 / j \neq i}^{N} v_{j}^{y_{j}}(\tau) *\left[\delta_{j i}(\tau) * m_{j i}^{y_{a i}}(\tau)+\delta_{i j}(\tau) * m_{i j}^{y_{d i}}(\tau)\right]
\end{aligned}
$$

$$
R^{y}(N, \tau)=\sum_{i=1}^{N} w_{i}^{y_{i}}(\tau) R_{i}^{y_{i}}(\tau)
$$

Where $u_{i}^{y_{i}}(\tau)$ is the total number of flights accommodated at the airport $(i), w_{i}^{y_{i}}(\tau)$ is the relative importance, $v_{i}^{y_{i}}(\tau)$ is the self-excluding importance, $R_{i}^{y_{i}}(\tau)$ is the resilience of an airport, and $R^{y}(N, \tau)$ is the resilience of the airport network.

\section{Optimization-based models}

In resilience modeling, optimization paradigm was applied to identify the most efficient way of improving the resilience of a system. Li et al. [90] investigated continuous network design problem (CNDP) in the context of transportation system resilience modeling. This model was able to attain higher accuracy in finding an optimal solution to the road capacity expansion with higher computation time which was efficient than many other models. Chen and Miller-Hooks [99] proposed a stochastic mixed-integer model for quantifying resilience by applying the concepts of Benders decomposition, column generation, and Monte Carlo simulation. This model was developed to maximize the post-disaster throughput of the system. The proposed methodology was applied to an intermodal freight network in the Western US. It was concluded that a higher recovery time and recovery budget could improve the resilience level from $5 \%$ to $100 \%$ of the pre-disaster level. As this model was applied based on a hypothetical recovery time and budget scenario and a lot of assumptions (logical but yet unproven in real-world), the implement ability of the model in real-world scenario need to be explored in future.

Several other studies proposed bi-level models to address network performance optimization problems during disasters (for example, [44, 46, 95]). However, the considerations of the number of constraints and their expression were substantially different in each study. In Faturechi and Miller-Hooks [46], a bi-level, a three-stage random model was proposed to evaluate and optimize travel time resilience in a roadway network based on the network's ability to resist and adapt to disruptions. The resilience was quantified in this article considering two conditions- considering a given budget $B$ for mitigation, preparedness, and response actions, and considering a given time $T$ for recovery action implementation. After any recovery activities in a post-disaster scenario, the performance of the transportation network reached a partial user equilibrium condition, and eq. (10) was used to measure the resilience. While Faturechi and MillerHooks [46] considered a response time constraint, predisaster capacity constraint, and retrofit cost constraint; Fan and Liu [44] considered feasibility constraint, flow constraint, and user equilibrium traffic flow constraint in the optimization problem formulation.

$$
R_{T, B}=\frac{t t^{r^{-1}}}{t t^{o^{-1}}}=\frac{\left(x^{o}, t^{o}\right)}{\left(x^{r}, t^{r}\right)}
$$

Where $t t^{r^{-1}}$ is the inverse of total travel time needed to reach a partial user equilibrium at the end of the response time, and $t t^{o^{-1}}$ is the inverse of total time to reach a user equilibrium representing pre-event and pre-actions.

Faturechi et al. [47] addressed the problem of resilience, specifically in the context of airport network under multiple meteorological damage scenarios. For rapid restoration, multiple functional criteria were considered, such as operational, budget, and physical resource limitations. The resilience formulation was developed by considering the expected demand in terms of incoming and outgoing flight flows in the post-repair scenario for a given repair time limitation and recovery budget. The model was applied to New York's LaGaurdia Airport pavement network system, and the analysis shows without any recovery activities taken, the airport was capable of accommodating 54\% pre-event takeoff and landing flow rate, where additional recovery activities and budget could increase flight handling capacity up to $84 \%$. The unique feature of this article was the inclusion of the airport network configuration, intra-connectivity of the different kinds of network links, and pavement condition in different scenarios.

Khaled et al. [80] modeled the resilience of the freight transportation system. An optimization model was developed to determine the optimal number of trains, routes, capacity variation considering operational constraints for congestion scenarios due to any disruptive events. As the model could include a large number of nodes and links, the proposed model was capable of solving the large-scale disruption scenarios (e.g., hurricane, flood) affecting a larger portion of the network. This approach was applied on a railroad network, which consists of 200 nodes and 478 links, and concluded that the proposed heuristic yielded efficient solutions.

$\mathrm{Xu}$ et al. [135] formulated an optimization model to determine the maximum and minimum bounds of network vulnerability. One key feature of this study was that the simultaneous disruptions on multiple links were considered in a two-level model, where the upper-level 
program maximized the remaining network throughput and the lower level program to maximize flow and identify the shortest paths.

\section{Summary of reviewed research articles}

All research articles reviewed in this paper are summarized in Table 2 in terms of research objectives, methods, key findings, study application domains, study areas, and disaster scenarios. In terms of research objectives, most studies attempted to analyze the criticality and vulnerability of transportation infrastructural components (e.g., nodes and links). Though some recent studies considered the impact of investment strategies or recovery strategies in resilience modeling, the perspective of resilience

Table 2 An overview of the reviewed research articles in this study

\begin{tabular}{|c|c|}
\hline Study aspects & Primary considerations \\
\hline \multirow[t]{7}{*}{ Research Objectives } & • Solving vehicle scheduling problem ([88], [93], [83], [38]) \\
\hline & - Assessing the criticality of infrastructure components ([117], [121], [138], [18], [108], [77], [84], [103], [134]) \\
\hline & • Developing post-disaster road restoration model ([136], [6], [90], [44], [95], [47]) \\
\hline & - Estimating reliability using uncertain parameters (e.g., link capacity, people's \\
\hline & • willingness to pay) ([118], [14], [31], [42], [32]) \\
\hline & • Analyzing vulnerability of the transportation network ([96], [113], [76], [87], [64], [81], [43], [134]) \\
\hline & • Developing resilience model ([132], [41], [141], [3], [72], [66], [26], [99], [73], [70]) \\
\hline \multirow[t]{11}{*}{ Methodology } & • Concept-based discussion ([27], [88], [96], [16], [113], [108], [106]) \\
\hline & • Uncertainty or probabilistic analysis-based model development ([1 18], [18], [15], [31], [32], [46], [19], [119]) \\
\hline & - Deterministic analysis of vulnerability or reliability ([81], [49]) \\
\hline & • Regressing model-based analysis [77] \\
\hline & - Simulation-based analysis of vulnerability or reliability ([138], [43], [103], [14]) \\
\hline & • Disutility function-based analysis [137] \\
\hline & - Sensitivity analysis of network reliability [42] \\
\hline & • Optimization function-based model development ([93], [83], [88], [121], [136], [6], [90], [44], [95], [46]) \\
\hline & - Population-based formulation to measure accessibility [117] \\
\hline & • Mathematical equation-based analysis ([132], [41]) \\
\hline & • GIS-based framework development [66] \\
\hline \multirow[t]{8}{*}{ Key findings } & $\begin{array}{l}\text { - Appropriate modeling tool can reduce computation time, cost or number of variables in solving rescheduling } \\
\text { problem in transportation system operation ([88], [93], [83]) }\end{array}$ \\
\hline & - Medium traffic demand condition shows larger drops in speeds compared to high demand case in disaster [121. \\
\hline & $\begin{array}{l}\text { - Restoration model determines the optimized restoration time of the road network by planning road trips in a } \\
\text { post-disaster scenario }([136],[6])\end{array}$ \\
\hline & $\begin{array}{l}\text { - Vulnerability index can be used to explore and detect the criticality/importance of different network } \\
\text { components ([76], [87], [18], [108], [81], [43], [77], [84], [31]) }\end{array}$ \\
\hline & $\begin{array}{l}\text { - Based on drivers' route choice behavior in a post-disaster scenario, the network capacity can be adjusted to } \\
\text { accommodate traffic demand at a required level of service [32] }\end{array}$ \\
\hline & • The impact of the disaster may vary significantly based on the region of the studied network system [132] \\
\hline & - Additional travel time for a trip can be used to measure the disaster impact [41] \\
\hline & $\begin{array}{l}\text { - Increased delay due to the disaster can occur in the post-disaster situation due to the congestion on reduced } \\
\text { functional links and nodes in a network [141] }\end{array}$ \\
\hline \multirow[t]{3}{*}{ Application domain } & • Roadway transportation ([117], [121], [66], [136], [6], [76], [81], [43], [77], [41], [27], [88], [83], [38], [18], [15], [132]) \\
\hline & • Railway transportation ([27], [88], [83], [38], [93], [18], [15], [87], [64]) \\
\hline & • Airway transportation (both passenger and freight) ([138], [108]) \\
\hline \multirow[t]{3}{*}{ Region of the study } & • Hypothetical Network ([27], [88], [83], [38], [93], [121]), [136], [118], [32]) \\
\hline & • Real-world road network system ([117], [76], [77], [81], [43], [84], [134], [6], [132], [8], [9]) \\
\hline & • Real-world subway system ([87], [64]) \\
\hline \multirow[t]{2}{*}{ Disaster scenarios } & • Natural Disaster ([16], [81], [90], [44], [95], [46], [47], [117], [77], [49], [132], [41]) \\
\hline & • Man-made events ([43], [77], [49], [14], [64], [31], [27], [88], [83], [38], [93], [121], [136], [6]) \\
\hline
\end{tabular}


evaluation has not changed much from determining the criticality/vulnerability of network components. In terms of the research methodology, optimization modeling technique was the most used analysis tool, since transportation systems are dynamic in nature and optimization modeling technique is suitable for dynamic system modeling. Due to the dynamic and uncertain travel behavior during a disaster, most studies relied on uncertainty and probabilitybased analysis.

Due to the scarcity of transportation system performance data from real disaster events, most literature considered hypothetical transportation networks and hypothetical disaster scenarios. However, few studies used real-world transportation system data in their modeling and analysis since 2010. As roadway transportation is the major mode of transportation for commuters and freights, most studies focused on resilience modeling of the surface transportation system. Several recent studies reported that pre-disaster planning activities could reduce disaster impacts. More research on types of predisaster planning activities and their relationship in different aspects of disaster impacts can assist the policymakers in developing investment strategies.

\section{Future research directions}

Though studies compiled in this study present the stateof-the-art transportation system resilience, many new research challenges are emerging and must be explored to improve resilience performance of evolving transportation systems and services by applying more advanced modeling techniques and using heterogeneous disaster and transportation system data. Based on the literature review, emerging aspects of the modern transportation system and future disaster forecasts, several key future research challenges are presented in the following subsections:

\section{(a) Consideration of Resiliency in the Transportation Planning Process}

As transportation planning is the first step in the development of a safe, efficient and resilient transportation network, it is imperative for engineers, planners, and policymakers to incorporate resiliency in transportation system planning from the very beginning of any longrange transportation planning. Though resiliency of transportation systems was studied for decades and many analyses and models were proposed, the number of articles that considered resilience concepts in transportation planning was very limited (for example, [72, 73]). Recognizing the importance of resiliency, the US Fixing America's Surface Transportation Act (FAST Act) mandated transportation planning organizations to consider resiliency in the planning process [50].
Understanding the consequences of more frequent and severe natural disasters and other climate changeinduced events (e.g., high summer temperature, winter bomb cyclone) are critical for the transportation system performance. Studies on the development of effective and reliable transportation planning strategies that improve resilience are vital for incorporating resilience in transportation planning.

Though climate-based disaster modeling is complex, the concept of a stochastic disaster scenario (developed using the past climate data) can be used in transportation resilience planning. Few studies, for example, Asadabadi and Miller-Hooks $[8,9]$ considered the impact of sea-level rise on the potential flood scenario in the Washington DC region and analyzed the resilience of transportation infrastructure in terms of future transportation investment planning. As climate change-induced disaster events are expected to increase in terms of frequency and severity (e.g., severe heat waves, amplified storm surges due to sea-level rise in coastal areas, and more intensified hurricanes and tornados), future research must develop effective climate response strategies addressing the forecasted challenges.

\section{(b) Ensuring Cyber Security}

Cybersecurity concern is one of the key challenges of the future mobility system. As connected and automated vehicles (CAVs) and supporting modern and intelligent transportation systems (ITS) are considered to be a major component of the future transportation system, it is important to minimize/eliminate cybersecurity threats that could compromise the security, the safety, and the privacy of the users and cyber-infrastructure functionality. Some incidents, like the recent hack of Tesla electric cars [13], demonstrated the danger of cybersecurity. There are 100 million lines of software codes running in some of the exiting advanced vehicle models [22]. Just a minor change in a single line of this code can lead to a fatal crash. With the connected transportation becoming more of a reality, the cybersecurity threats to this sector are on the rise [68]. Beyond transportation infrastructure, CAV will be connected to cloud services to support many applications related to vehicle operation, safety, and performance. As the failure of the communication network, partially or fully due to cyber-attacks, can lead to failure of the total mobility system, the importance of cyber threat resilience of the future mobility system is paramount. Though the research on cybersecurity does not fall on the domain of transportation research, future research direction must involve a significant amount of collaborative efforts between multidisciplinary researchers to incorporate both the resilience principles and cybersecurity concepts in developing future connected transportation system. 


\section{(c) Resilience in Interdependent Critical Infrastructures}

The transportation system, one of the largest critical infrastructures, is closely interconnected with other critical infrastructures such as communication networks, power systems. In general, interdependency modeling considers interconnectivity among multiple infrastructure systems. However, the interdependency concept is still new in resilience studies. As future mobility system analysis will be more dependent on information technology and related infrastructure, addressing additional vulnerability due to energy infrastructure (e.g., power outage), communication networks must be explored in an integrated and multidisciplinary environment. Some of the critical research questions to be explored in future studies include (i) identification of the extent and manner of interdependency between different infrastructure systems and analysis of the resilience of the transportation systems based on the exposure; (ii) evaluation of system performance due to the partial impairment of single or multiple interconnected systems; and (iii) development of engineering solutions to minimize failure risk of interdependent infrastructures.

\section{(d) Post-disaster Traveler Route Choice}

The capacity of the road network reduces, and trip travel time increases significantly after any disaster event. In the disaster aftermath, the total recovery time requirement is largely dependent on the damage extent as well as on the efficient use of post-disaster network capacity. Post-disaster network capacity ensures the efficient utilization of recovery efforts and recovery teams so that recovery can be achieved quickly. Generally, post-disaster capacity depends greatly on the traveler route choice behavior after a disaster [137]. Therefore, understanding a community's route choice decisionmaking and behavior can bring two benefits: balancing the community's transportation demand after a disaster and determining network segments to be repaired first depending upon community's route choice preference.

\section{(e) Quantification of Resilience Considering Connected and Automated Vehicle (CAV) Technology}

CAV technology is expected to revolutionize surface transportation systems and will enable many emerging mobility service options. No research study explored the impact of CAV technology on transportation system resilience. Therefore, understanding and quantification of impacts of partial and full deployment of CAV technology in transportation system resiliency performance are critical. Besides, mixed traffic conditions (i.e., a mix of traditional vehicles and CAVs) during the transition can make resilience quantification more complicated and challenging. During the evacuation phase, evacuation traffic creates long queues along evacuation routes due to a lack of information about traffic conditions. With the deployment of CAV, the transportation infrastructure can evacuate a relatively large number of people through real-time information exchange. As the expected revolutionary changes of CAV technology are undeniable, future studies must explore their impacts on the users' travel behaviors and implications on future transportation system resilience planning.

\section{Conclusions}

A comprehensive review on the transportation system resilience in terms of system resilience characteristics in response to different types of disaster was performed in this paper. Different modeling concepts, different parameters and system response variables were used in quantifying system resilience, and future research directions were identified. Over the past decades, researchers, engineers, and practitioners made advancements in the quantification of resilience and determined ways of enhancing the resilience of a network system. This review reveals that the vast majority of the scholarly literature on the resilience of transportation system published since 2006 deal with the highway-based transportation system. Because of technological advancement (e.g., availability of mobility data) and computational power, the resilience analysis of large-scale disruption scenarios become comparatively easy. Vulnerability is one of the most explored performance parameters/index in transportation system resilience studies. In the case of resilience analysis using real disaster data, hurricane impacts weres widely explored due to its predictability, relatively longer warning time before landfall, and widespread disaster impacts. In recent studies, researchers have considered real-world complex and large network system in the resilience analysis. Future transportation resilience modeling will become more complex and challenging due to the deployment of emerging technologies such as CAV in future mobility systems, cybersecurity issues, and the growing frequency and magnitude of natural disasters.

\footnotetext{
Abbreviations

CAV: Connected and Automated Vehicle; CBN: Connection-Based Network; CNDP: Continuous Network Design Problem; DPM: Disrupted Passenger Metric; DSER: Direct Static Economic Resilience; DYNASMART-P: Dynamic Network Assignment-Simulation Model for Advanced Roadway Telematics (Planning version); DVRSP: Dynamic Vehicle Rescheduling Problem; FAST Act: Fixing America's Surface Transportation Act; FHWA: Federal Highway Admisinstration; FRAM: Functional Resonance Analysis Method; GIS: Geographical Information System; GPS: Glonal Positionign Systems; GRASP: Greedy Randomized Adaptive Search Procedure; IP: Integer Programming; ITS: Intelligent Transportation Systems; LoR: loss-of-Resilience;
} 
MPS: Most Probable State; MVE: Most Vital Edge; MVN: Most Vital Node; NRC : National Research Council; NYC: New York City; O-D: Origin-Destination; RAG: Resilience Analysis Grid; RCL: Restricted Candidate List; ROMA: Railway traffic Optimization by Means of Alternative; SI: Systematic Impact; TRE: Total Recovery Effort; TSN: Time-Space Network; USGS: U.S. Geological Survey; USGCRP: U.S. Global Change Research Program; US NOAA: U.S. National Oceanic and Atmospheric Administration; VND: Variable Neighborhood Descent; VNS: Variable Neighborhood Search; VRSP: Vehicle Rescheduling Problem; VSP: Vehicle Scheduling Problem; VSRP: Vessel Schedule Recovery Problem

\section{Acknowledgements}

Not Applicable.

\section{Authors' contributions}

KD developed the paper concept, SA reviewed the articles and developed the paper under KD's supervision. Both authors approved the draft contents.

\section{Authors' information}

Not Applicable.

\section{Funding}

Dr. Dey's startup fund provided by West Virginia University.

\section{Availability of data and materials}

Not Applicable.

\section{Competing interests}

Not Applicable.

Received: 6 February 2020 Accepted: 20 May 2020

Published online: 22 June 2020

\section{References}

1. Abdelghany KF, Abdelghany AF, Ekollu G (2008) An integrated decision support tool for airlines schedule recovery during irregular operations. Eur J Operational Res 185:825-848

2. Adams TM, Bekkem KR, Duran EJT (2012) Freight Resilience Measures. J Transportation Eng 138(11):1403-1409

3. Adjetey-Bahun K, Birregah B, Châtelet E, Planchet JL, Laurens-Fonseca $\mathrm{E}$ (2014) A simulation-based approach to quantifying resilience indicators in a mass transportation system. In: ISCRAM

4. Adjetey-Bahun K, Birregah B, Chatelet E, Planchet JL (2016) A model to quantify the resilience of mass transportation systems. Reliabil Eng Syst Safety 153:1-14

5. Ahmed S, Dey K, Fries R (2019) Evaluation of transportation system resilience in the presence of connected and automated vehicles. Transp Res Rec 2673(9):562-574

6. Aksu DT, Ozdamar L (2014) A mathematical model for post-disaster road restoration: Enabling accessibility and evacuation. Transportation Research Part E 61:56-67

7. Ariano AD, Pranzo M (2009) An Advanced Real-Time Train Dispatching System for Minimizing the Programming of Delays in a Dispatching Area Under Severe Disturbances. Netw Spat Econ 9(1):63-84

8. Asadabadi A, Miller-Hooks E (2017a) Assessing strategies for protecting transportation infrastructure from and uncertain climate future. Transportation Research Part A 105:27-41

9. Asadabadi A, Miller-Hooks E (2017b) Optimal transportation and shoreline infrastructure investment planning under a stochastic climate future. Transp Res B Methodol 100:156-174

10. Asadabadi A, Miller-Hooks E (2018) Co-opetition in enhancing global port network resiliency: a multi-leader, common-follower game theoretic approach. Transp Res B Methodol 108:281-298

11. Ayyub BM (2014) Systems resilience for multihazard environments: Definition, metrics, and valuation for decision making. Risk Analysis J 34(2): 340-355. https://doi.org/10.1111/risa.12093 2014 (Epub 2013 Jul 22)

12. Balakrishnan A, Mirchandani P, Natarajan P (2009) Connectivity upgrade models for survivable network design. Oper Res 57(1):170-186

13. BBC http://www.bbc.com/news/technology-37426442. Accessed 15 Dec 2018
14. Bell MGH (1999) Measuring network reliability: A game theoretic approach. Advanc Transp 33(2):135-146

15. Berche B, Ferber CV, Holovatch T, Holovatch Y, (2012) Transportation network stability: a case study of city transit. Advances in Complex Systems 15 (supp01):1250063

16. Berdica K (2002) An introduction to road vulnerability: what has been done, is done and should be done. Transport Policy 9(2):117-127

17. Bertossi AA, Carraresi P, Gallo G (1987) On some matching problems arising in vehicle scheduling models. Networks 17(3):271-281

18. Berche B, von Ferber C, Holovatch T, Holovatch $Y$ (2009) Resilience of Public transport networks against attacks. Eur Physical Journal B 71:125-137

19. Bhavathrathan BK, Patil GR (2015) Capacity uncertainty on urban road networks: A critical state and its applicability in resilience quantification. Comput Environ Urban Syst 54:108-118

20. Blalock G, Kadiyali V, Simon DH (2007) The impact of post 9/11 airport security measures on the demand for air travel

21. Bodin, L. D., \& Rosenfield, D. (1976). Estimation of the operating cost of mass transit systems (no. WAHCUPS-UMTA-1-76 final Rpt.)

22. Bonne, A., P. Blythe, N. Choudhary, P. Davis, P. Edwards, M. Thomas, D. Wong, 2017 Connected and autonomous vehicles : a hacker 's delight. https://gowlingwlg.com/GowlingWLG/media/UK/pdf/autodrive/170907cyber-security-white-paper.pdf

23. Bratu S, Barnhart C (2006) Flight operations recovery: New approaches considering passenger recovery. J Scheduling 9(3):279-298

24. Brouer BD, Dirksen J, Pisinger D, Plum CEM, Vaaben B (2013) The Vesse Schedule Recovery Problem (VSRP)- A MIP model for handling disruptions in linear shipping. Eur J Operational Res 224(2):362-374

25. Bruneau M, Chang SE, Eguchi RT, Lee GC, O'Rourke TD, Reinhorn AM, Shinozuka M, Tierney K, Wallace WA, Winterfeldt DV (2003) A framework to quantitatively assess and enhance the seismic resilience of communities. Earthq Spectra 19(4):733-752

26. Brabhaharan P (2006) Recent advances in improving the resilience of road networks. New Zealand Society of Earthquake Engineering Conference

27. Bunte, S., and Kliewer, N. (2009). /. Public transport, Vol: 1, Issue: 4, pp: 299-317

28. Caplice, C., J. B. Rice, B. Ivanov, E. Stratton, (2008) Development of a statewide freight system resiliency plan, , MIT Center for Transportation and Logistics

29. Carpaneto G, Dell'Amico M, Fischetti M, Toth P (1989) A branch and bound algorithm for the multiple depot vehicle scheduling problem. Networks 19(5):531-548

30. Chang SE (2003) Transportation planning for disasters: an accessibility approach. Environ Plan A 35(6):1051-1072

31. Chen A, Yang H, Lo HK, Tang WH (1999) A capacity related reliability for transportation networks. J Advanc Transp 33(2):183-200

32. Chen A, Yang H, Hong KL, Tang WH (2002) Capacity reliability of a road network: an assessment methodology and numerical results. Transportation Research Part B 36(3):225-252

33. Chen, L., E. Miller-Hooks, 2012 Resilience: An Indicator of Recovery Capability in Intermodal Freight Transport, Transportation Sci, Vol: 46, Issue: 1, pp: 109-123

34. Clausen J, Larsen A, Larsen J, Rezanova NJ (2010) Disruption management in the airline industry-Concepts, models and methods. Comp Operations Res 37:809-821

35. Clark, D. E., J. M. McGibany, A. Myers, 2009 The effects of 9/11 on the Airline Travel Industry, The Impact of 9/11 on Business and Economics, pp: 75-86

36. Comfort LK (1994) Risk and resilience: inter-organizational learning following the Northridge earthquake of 17 January 1994. J Contingencies Crisis Manag 2(3):157-170

37. Cox A, Prager F, Rose A (2011) Transportation security and the role of resilience: A foundation for operational metrics. Transport Policy 18:307-317

38. David B, Kresz M (2017) The dynamic vehicle rescheduling problem. CEJOR 25:809-830

39. Daduna, J. R., \& Paixão, J. M. P. (1995). Vehicle scheduling for public mass transit—an overview. In computer-aided transit scheduling (pp. 76-90). Springer, Berlin, Heidelberg

40. Dekker S, Hollnagel E, Woods D, Cook R (2008) Resilience engineering: new directions for measuring and maintaining safety in complex systems. Lund University School of Aviation

41. Donovan B, Work DB (2017) Empirically quantifying city-scale transportation system resilience to extreme events. Transportation Research Part C 79:333346 
42. Du ZP, Nicholson AJ (1997) Degradable transportation systems: sensitivity and reliability analysis. Transportation Research Part B 31(3):225-237

43. El-Rashidy RA, Grant-Muller SM (2014) An assessment method for highway network vulnerability. J Transport Geography 34:34-43

44. Fan Y, Liu C (2010) Solving stochastic transportation network protection problems using the progressive hedging -based method. Netw Spat Econ 10:193-208

45. Faturechi R, Miller-Hooks E (2014) Measuring the performance of transportation infrastructure systems in disasters: a comprehensive review. J Infrastruct Syst 21(1):04014025

46. Faturechi R, Miller-Hooks E (2014) Travel time resilience of roadway networks under disaster. Transportation Research Part B 70:47-64

47. Faturechi R, Levenberg E, Miller-Hooks E (2014) Evaluating and optimizing resilience of airport pavement networks. Comp Operations Res 43:335-348

48. Fekete SP, Kroller A, Lorek M, Pfetsch M (2011) Disruption management with rescheduling of trips and vehicle circulations

49. Fekete A, Tzavella K, Baumhauer R (2016) Spatial exposure aspects contributing to vulnerability and resilience assessments of urban critical infrastructure in a flood and blackout context. Nat Hazards 86:151-176

50. FHWA, Fixing America's Surface Transportation Act. (https://www.fhwa.dot. gov/fastact/). Accessed 15 Dec 2018

51. Filar, J. A., P. Manyem, D. M. Panton, K. White,2007 A Model for Adaptive Rescheduling of Flights in Emergencies (MARFE), J Industrial and Manag Optimization, Vol: 3, Issue: 2, pp: 335-356

52. Fischetti, M., Lodi, A., \& Toth, P. (1999). A branch-and-cut algorithm for the multi depot vehicle scheduling problem. Technical report

53. Fischetti M, Lodi A, Martello S, Toth P (2001) A polyhedral approach to simplified crew scheduling and vehicle scheduling problems. Manag Sci 47(6):833-850

54. Forbes MA, Holt JN, Watts AM (1994) An exact algorithm for multiple depot bus scheduling. Eur J Oper Res 72(1):115-124

55. Freling R, Wagelmans AP, Paixão JMP (2001) Models and algorithms for single-depot vehicle scheduling. Transp Sci 35(2):165-180

56. Fu X, Lam WH (2018) Modelling joint activity-travel pattern scheduling problem in multi-modal transit networks. Transportation 45(1):23-49

57. Gao H, Chen Y, Mei S, Huang S, Xu Y (2017) Resilience-oriented prehurricane resource allocation in distribution systems considering electric buses. IEEE 105(7):1214-1233

58. Garcia R, Almodovar M, Parreno F (2009) Heuristic Algorithm for Coordination in Public Transport under Disruptions, Workshops on Application of Evolutionary Computation, pp 808-817

59. Gintner V, Kliewer N, Suhl L (2005) Solving large multiple-depot multiplevehicle-type bus scheduling problems in practice. OR Spectrum 27(4):507523

60. Goodchild, A., E. Jessup, E. McCormack, 2009 Washington State Freight System Resiliency, Final technical report, Washington State Department of Transportation

61. Gu, Y., Fu, X., Liu, Z., Xu, X., \& Chen, A. (2020). Performance of transportation network under perturbations: reliability, vulnerability, and resilience, Transportation Research Part E: Logistics and Transportation Review, 133

62. Hadjar A, Marcotte O, Soumis F (2006) A branch-and-cut algorithm for the multiple depot vehicle scheduling problem. Oper Res 54(1):130-149

63. Haghani A, Banihashemi M (2002) Heuristic approaches for solving largescale bus transit vehicle scheduling problem with route time constraints. Transp Res A Policy Pract 36(4):309-333

64. Han, C., L. Liu, 2009 Topological vulnerability of subway networks in China, IEEE Explore

65. Hansen P, Mladenovic N, Perez JAM (2008) Variable neighborhood search: methods and application. 4OR 6(4):319-360

66. Heaslip K, Louisell W, Collura J (2009) A methodology to evaluate transportation resiliency for regional network, 88th Transportation Research Board Annual Meeting

67. Hoffstadt, J. (1981). Computerized vehicle and driver scheduling for the hamburger Hochbahn Aktiengesellschaft. Computer scheduling of public transport, 35-52

68. Holmes, M. 2017 https://www.satellitetoday.com/telecom/2017/07/21/ transportation-sector-not-taking-cyber-threat-seriously-enough/

69. Hosseini S, Barker K, Ramirez-Marquez JE (2016) A review of definitions and measures of system resilience. Reliab Eng Syst Saf 145:47-61

70. Hughes, J. F., \& Healy, K. (2014). Measuring the resilience of transport infrastructure (No. 546)
71. Hu ZH (2010) A container multimodal transportation scheduling approach based on immune affinity model for emergency relief. Expert Syst Applications 38:2632-2639

72. Ibanez E, McCalley JD (2011) Multiobjective evolutionary algorithm for longterm planning of the national energy and transportation systems. Energy Systems 2(2):151-169

73. Ibanez E, Lavrenz S, Gkritza K, Meija-Giraldo DA, Krishnan V, McCalley JD, Somani AK (2016) Resilience and robustness in long-term planning of the national energy and transportation system. Int J Critical Infrastructure 12(1/ 2):82-103

74. Jacobs, J., 2004 Reducing delays by means of computer-aided 'on-the-spot' rescheduling, WIT press, pp: 603-612

75. Janic M (2015) Modeling the resilience, friability and costs of an air transport network affected by a large-scale disruptive event. Transportation Research Part A 71:1-16

76. Jenelius E, Mattsson L (2012) Road network vulnerability analysis of area covering disruptions: A grid based approach with case study. Transportation Research Part A 46:746-760

77. Jenelius E (2009) Network structure and travel patterns: explaining the geographical disparities of road network vulnerability. J Transport Geography 17:234-244

78. Jin JG, Tang LC, Sun L, Lee DH (2014) Enhancing metro network resilience via localized integration with bus services. Transportation Research Part E 63:17-30

79. Kavousi-Fard A, Wang M, Su W (2018) Stochastic resilient post-hurricane power system recovery based on mobile emergency resources and reconfigurable networked microgrids. IEEE Access 6:72311-72326

80. Khaled AA, Jin M, Clarke DB, Hoque MA (2015) Train design and routing optimization for evaluating criticality of freight railroad infrastructures. Transportation Research Part B 71:71-84

81. Khademi N, Balaei B, Shahri M, Mirzaei M, Sarrafi B, Zahabiun M, Mohaymany AS (2015) Transportation network vulnerability analysis for the case of a catastrophic earthquake. Int J Disaster Risk Reduction 12:234-254

82. Kliewer, N., Mellouli, T., \& Suhl, L. (2002). A new solution model for multidepot multi-vehicle-type vehicle scheduling in (sub) urban public transport. In Proceedings of the 13th Mini-EURO Conference. Politechnic of Bari

83. Kliewer, N., T. Mellouli, L. Suhl, 2006 A time-space network based exact optimization model for multi-depot bus scheduling, Eur J Operational Res, Vol: 175, issue: 3, pp: 1616-1627

84. Knoop VL, Snelder M, van Zuylen HJ, Hoogendoorn SP (2012) Link-level vulnerability indicators for real-world networks. Transportation Research Part A 46:843-854

85. Kohl N, Larsen A, Larsen J, Ross A, Tiourine S (2007) Airline disruption management- Perspectives, experiences and outlook. J Air Transp Manag 13:149-162

86. Lam NNS, Reams M, Li K, Li C, Mata LP (2015) Measuring community resilience to coastal hazards along the northern Gulf of Mexico. Natural Hazards Review 17(1):04015013

87. Latora, V., M. Marchiori, 2005 Vulnerability and protection of infrastructure networks, Physical review, Vol: 71

88. Li, J. Q., P. B. Mirchandani, D. Borenstein, 2008 Parallel Auction Algorithm for Bus Scheduling, Computer-aided System Public Transport, pp: 281-299

89. Li, C., X. Qi, D. P. Song, 2014 Real-time scheduling and rescheduling in linear shipping service with regular uncertainties and disruption events, , Working paper, The Hong Kong University of Science and Technology

90. Li C, Yang H, Zhu D, Meng Q (2012) A global optimization method for continuous network design problems. Transportation Research Part B 46: 1144-1158

91. Lida, Y., H. Wakabayashi, 1989 An approximation method of terminal reliability of road network using partial minimal path and cut set, Proceedings of the Fifth WCTR, pp: 367-380

92. Liu Z, Chen X, Meng Q, Kim I (2018) Remote park-and-ride network equilibrium model and its applications. Transp Res B Methodol 117:37-62

93. Lobel (1997) Optimal vehicle scheduling in public transit, PhD Thesis

94. Löbel A (1998) Vehicle scheduling in public transit and Lagrangean pricing. Manag Sci 44(12-part-1):1637-1649

95. Lo H, Tung Y (2003) Network with degradable links: capacity analysis and design. Transportation Research Part B 37:345-363

96. Mattsson LG, Jenelius E (2015) Vulnerability and resilience of transport systemsA discussion of recent research. Transportation Research Part A 81:16-34 
97. Meyer, M. D.,2008 The Nation's transportation system as a security challenge, Wiley Handbook of Science and Technology for Homeland Security

98. MIT Center for Transportation and Logistics. 2006 Development of a statewide freight system resiliency plan, Final research report

99. Miller-Hooks, E., X. Zhang, R. Faturechi, 2012 Measuring and maximizing resilience of freight transportation networks, Comput Operations Res, Vol: 39, pp: 1633-1643

100. Murray-Tuite, P. M. (2006). A comparison of transportation network resilience under simulated system optimum and user equilibrium conditions. In simulation conference, 2006. WSC 06. Proceedings of the winter (pp. 1398-1405). IEEE

101. Murray-Tuite, P. M., 2008 Transportation Network Risk Profile for an OriginDestination Pair: Security Measures, Terrorism, and Target and Attack Method Substitution, Transportation Research Board, pp: 19-28

102. Murray-Tuite, P. M., 2007 A framework for evaluating risk to the transportation network from terrorism and security policies Int J Critical Infrastructures, Vol: 3, Issue: 3/4, pp: 389-407

103. Murray-Tuite, P. M., H. S. Mahmassani, 2004 Methodology for determining vulnerable links in a transportation network. J Transportation Res Board, pp: 88-96

104. National research council https://www.nap.edu/resource/12781/ClimateChange-Lines-of-Evidence.pdf. Accessed 15 Dec 2018

105. Nemeth, C. (2016). Resilience engineering: the birth of a notion. In Resilience Engineering Perspectives, Volume 1 (pp. 17-24). CRC press

106. Noland RB, Polak JW (2002) Travel time variability: a review of theoretical and empirical issues. Transport Reviews 22(1):39-54

107. Omer M, Mostashari A, Nilchiani R (2013) Assessing resilience in a regional road-based transportation network. Int J Industrial Syst Eng 13(4):389-408

108. O'Kelly ME (2015) Network hub structure and resilience. Netw Spat Econ 15: 235-251

109. Orloff CS (1976) Route constrained fleet scheduling. Transp Sci 10(2):149168

110. Oukil A, Amor HB, Desrosiers J, El Gueddari H (2007) Stabilized column generation for highly degenerate multiple-depot vehicle scheduling problems. Comput Oper Res 34(3):817-834

111. Patil, G. R., \& Bhavathrathan, B. K. (2016). Effect of traffic demand variation on road network resilience. Advances in complex systems, 19(01n02), 1650003

112. Qi X (2015) Disruption Management for Linear Shipping, Handbook of Ocean Container Transport Logistics, pp 231-249

113. Reggiani, 2013 Network resilience for transport security: Some methodological considerations Transport Policy 28: 63-68

114. Rodrigue, J. P. (2017), New York: Routledge, 440 pages. ISBN 9781138669574

115. Saha JL (1972) An algorithm for bus scheduling problems. J Oper Res Soc 21(4):463-474

116. Silva GP, Wren A, Kwan RS, Gualda NDF (1999) Bus scheduling based on an arc generation-network flow approach. University of Leeds-School of Computer Studies, Technical report

117. Sohn J (2006) Evaluation of the significance of highway network links under the flood damage: An accessibility approach. Transportation Research Board A 40(6):491-506

118. Soltani-Sobh A, Heaslip K, Khoury JE (2015) Estimation of road network reliability on resiliency: An uncertain based model. Int J Disaster Risk Reduction 14:536-544

119. Sultania, G., B. K. Bhavathrathn, G. R. Patil, 2014 Quantifying risk due to capacity uncertainty on urban road networks. 11th Transportation Planning and Implementation Methodologies for Developing Countries, pp: 539-547

120. Timmermann P (1981) Vulnerability, resilience and the collapse of society. Environ Monograph 1:1-42

121. Ukkusuri SV, Yushimito WF (2009) A methodology to assess the criticality of highway transportation networks. J Transportation Security 2(1-2):29-46

122. USGCRP, 2018: Impacts, risks, and adaptation in the United States: fourth National Climate Assessment, volume II [Reidmiller, D.R., C.W. Avery, D.R. Easterling, K.E. Kunkel, K.L.M. Lewis, T.K. Maycock, and B.C. Stewart (eds.)]. U. S. global change research program, Washington, DC, USA. doi: https://doi. org/10.7930/NCA4.2018

123. USGS https://web.archive.org/web/20151003064028/http://earthquake.usgs. gov/earthquakes/eqarchives/year/2008/2008_deaths.php. Accessed 15 Dec 2018
124. US NOAA https://www.nhc.noaa.gov/outreach/history/. Accessed 15 Dec 2018

125. US NOAA https://www.ncdc.noaa.gov/billions/events/US/2017. Accessed 15 Dec 2018

126. US NOAA https://www.ncdc.noaa.gov/billions/events/US/2012. Accessed 15 Dec 2018

127. US NOAA https://www.ngdc.noaa.gov/nndc/struts/results?eq_0 =7843\&t= $101650 \& s=13 \& d=22$. Accessed 15 Dec 2018

128. Vernimmen B, Dullaert W, Engelen S (2007) Schedule unreliability in linear shipping: Origins and consequences for the hinter land supply chain. Maritime Econ Logistics 9:193-213

129. Visentini MS, Borenstein D, Li JQ, Mirchandani PB (2014) Review of real-time vehicle schedule recovery methods in transportation services. J Sched 17(6): 541-567

130. Vranas PBM, Bertsimas D, Odoni AR (1994a) The Multi-Airport GroundHolding Problem in Air Traffic Control. Operations Research 42:249-261

131. Vranas PBM, Bertsimas D, Odoni AR (1994b) Dynamic Ground Holding Policies for a Network of Airports. Transportation Sci 28:275-291

132. Vugrin ED, Warren DE, Ehlen MA (2011) A resilience assessment framework for infrastructure and economic systems: Quantitative and qualitative resilience analysis of petrochemical supply chains to a hurricane. Am Institute Chemical Eng 30(3):280-290

133. Wan C, Yang Z, Zhang D, Yan X, Fan S (2018) Resilience in transportation systems: a systematic review and future directions. Transp Rev 38(4):479-498

134. Wang, Z., A. P. C. Chan, J. Yuan, B. Xia, M. Skitmore, Q. Li, 2014 Recent advances in modeling the vulnerability of transportation networks, J Infrastructure systems, Vol: 21, Issue: 2

135. Xu X, Chen A, Yang C (2017) An optimization approach for deriving upper and lower bounds of transportation network vulnerability under simultaneous disruptions of multiple links. Transportation Research Procedia 23:645-663

136. Yan S, Shih YL (2009) Optimal scheduling of emergency roadway repair and subsequent relief distribution. Comput Operations Res 36:2049-2065

137. Yin, Y., H. Leda, 2001 Assessing performance reliability of road networks under nonrecurrent congestion, Transportation Research Record 1771, pp: $148-155$

138. Yoo S, Yeo H (2016) Evaluation of the resilience of air transportation network with adaptive capacity. Int J Urban Sci 20:38-49

139. Zhang X, Mahadevan S, Goebel K (2019) Network reconfiguration for increasing transportation system resilience under extreme events. Risk Anal 39(9):2054-2075

140. Zheng YJ, Ling HF (2013) Emergency transportation planning in disaster relief supply chain management: a cooperative fuzzy optimization approach. Soft Computing 17(7):1301-1314

141. Zhu, Y., K. Xie, K. Ozbay, F. Zuo, H. Yang, 2017 Data-Driven Spatial Modeling for Quantifying Networkwide Resilience in the Aftermath of Hurricanes Irene and Sandy. Transportation Research Board. 9-18

\section{Publisher's Note}

Springer Nature remains neutral with regard to jurisdictional claims in published maps and institutional affiliations.

\section{Submit your manuscript to a SpringerOpen ${ }^{\circ}$ journal and benefit from:}

- Convenient online submission

- Rigorous peer review

- Open access: articles freely available online

High visibility within the field

- Retaining the copyright to your article

Submit your next manuscript at $>$ springeropen.com 